\title{
ПАЛИНОЛОГИЧЕСКАЯ ХАРАКТЕРИСТИКА ДАУГАВСКИХ ОТЛОЖЕНИЙ ВЕРХНЕГО ДЕВОНА ЛАТВИИ И ПСКОВСКОЙ ОБЛАСТИ РОССИИ
}

\author{
М. Г. Раскатова \\ Воронежский государственный университет \\ Поступила в редакцию 13 февраля 2019 г.
}

\begin{abstract}
Аннотация: в статье дана палинологическая характеристика даугавских отложений франского яруса верхнего девона из разрезов 3 скважсин на территории Латвии и Псковской области России. Даугавский горизонт охарактеризован 2 миоспоровыми зонами, установленными для ВосточноЕвропейской платформы (ВЕП). Сравнительный анализ изменения видового состава выделенных комплексов миоспор позволил дополнить характеристику даугавских отложений, кроме того полученные данные позволили осуществить корреляцию даугавских отложений, развитых на территории Главного девонского поля (ГДП), с одновозрастными аналогами в пределах Центрального девонского поля (ЦДП).
\end{abstract}

Ключевые слова: миоспоры, биостратиграфия, даугавский горизонт, Латвия, Псковская область России.

\section{PALINOLOGICAL CHARACTERISTIC OF THE UPPER DEVONIAN DAUGAVA DEPOSITS OF LATVIA AND PSKOV REGION OF RUSSIA}

\begin{abstract}
Dangava deposits of the Upper Devonian Frasnian stage from the sections of 3 wells in the territory of Latvia and the Pskov region of Russia. The Daugava RS is characterized by 2 miospore zones established for the East European Platform. Comparative analysis of changes in the species composition of the isolated complexes of miospores allowed to supplement the characteristic of the Dangava deposits. This data made it possible to correlate the Daugava deposits in the territory of the Main Devonian field with the same-aged analogues within the Central Devonian field.
\end{abstract}

Key words: miospores, biostratigraphy, Daugava RS, Latvia, Pskov Region of Russia.

\section{Введение}

Впервые даугавский горизонт был выделен К. Гревингком [1, 2] как «верхний водопадный горизонт» бассейна р. Даугава. Э. Краус [3] обозначил горизонт индексом «d» и впоследствии подразделил разрез на 4 подгоризонта: c2, d1, d2, d3. Это единое для всего северо-запада Русской платформы хроностратиграфическое подразделение объединяло порховские, свинордские, ильменские, бурегские и альтовские слои и их стратиграфические аналоги. Даугавский горизонт в ранге надгоризонта предложен В. С. Сорокиным [4, 5, 6]. Типовым литостратиграфическим подразделением комплексного обоснования является выделенная П. П. Лиепиньшем [7] даугавская свита Центральной Латвии. Название свиты происходит от р. Даугава, по берегам которой даугавский горизонт наиболее полно и детально изучен в многочисленных обнажениях и буровых сква- жинах. Стратотипическим разрезом горизонта служит стратотип даугавской свиты - сплошная полоса обнажений в окрестностях г. Плявиняс, на крыльях Плявиньского поднятия. Стратотип и основные типовые разрезы горизонта описаны Н. В. Делле, П. П. Лиепиньшем и В. С. Сорокиным. Систематическое изучение миоспоровых комплексов из верхнедевонских отложений Латвии началось с исследований В. Р. Озолини [8]. Для франских отложений Латвийской ССР ею были выделены 5 споровопыльцевых комплексов, в том числе III - для даугавской свиты. Палинокомплекс был проиллюстрирован зарисовками миоспор. Работа В. Р. Озолини имеет большое значение, т.к. впервые для Латвии была показана возможность расчленения франских отложений по миоспорам. Кроме того, выделенные Озолиней комплексы миоспор были важны для сравнительного анализа. 


\section{Материалы и методы}

Анализ миоспор из даугавских отложений проводился по двум скважинам в Латвии: №5 - район г. Бауски и № 1-Т - г. Даугавпилс (15 образцов из двух разрезов) и в Псковской области - № 9 Великолукский район (4 образца). В даугавских отложениях из латвийских разрезов $35 \%$ проб содержали значительное количество миоспор (180-200). В разрезе скважины: №9 - содержание миоспор более высокое (до 250).

Препараты изученных миоспор из даугавских отложений Латвии №L2011д/29-31 и Псковской области России №П2011д/9 хранятся в лаборатории микропалеонтологии кафедры исторической геологии и палеонтологии геологического факультета Воронежского государственного университета.

\section{Предварительная палинологическая характеристика даугавских отложений}

В составе даугавского горизонта в Псковской области преобладают органогенные, органогеннодетритовые и хемогенные известняки, в Латвии метасоматические и седиментационные доломиты. По этапно-формационному признаку даугавский горизонт объединяет порховские-альтовские слои в единый формационный комплекс. Он отвечает времени нарастания и наиболее широкого распространения среднефранской трансгрессии на северо-западе Русской платформы [9].

Первоначально изучение отложений даугавского горизонта на присутствие миоспор проводилось нами из ильменских отложений (средняя часть даугавского горизонта) Псковской области (скв. 9) для которой автором был выделен комплекс миоспор [10].

Ильменские отложения были исследованы из скважины, расположенной на северо-восточном склоне Белорусского свода (скв. №9, инт. 87,8-103 м c. Ваши Великолукского района Псковской области).

Разрез верхнедевонских отложений, вскрытый скв. 9, является промежуточным и был обработан с целью облегчения корреляции ильменских отложений Прибалтики с одновозрастными аналогами в пределах Центрального девонского поля.

Ильменские отложения в разрезе данной скважины представлены глинами голубыми, известковистыми с ходами илоедов, остатками обугленной флоры, мелких тентакулитов и их отпечатков. В верхней части разреза преобладают слабоглинистые известняки с тонкой волнисто-линзовидной слоистостью, монолитные с прослоями голубовато-серых комковатых мергелей, которые покрыты скоплениями раковин замковых брахиопод. Общая мощность ильменских слоев 15,2 м. Граница между ильменскими и подстилающими свинордскими слоями проводится условно.

В разрезе скв. 9 содержится фауна брахиопод Cyrtospirifer schelonicus Nal., Lingula sp. и фауна пелеципод Aviculopecten sp., Aviculoidea sp., в глинистых прослоях найден зуб рыбы размером до 0,5 см.
Из этих отложений М. К. Погребняк определен комплекс остракод, типичный для ильменских отложений Главного девонского поля, среди которых присутствует значительное количество форм, широко распространенных в семилукских отложениях ЦДП. К ним относятся: Mossolovella philippovae Egor., Indivisia indistincta Gleb. et Zasp., Acratia galinae Egor., A. gibba Gleb. et Zasp., Aparchites calculus Gleb. et Zasp., Pseudonodella plana Gleb. et Zasp., Mennerella krestovnikovii Egor.

Комплекс миоспор, выделенный из ильменских отложений Псковской области демонстрирует богатый таксономический состав: Calamospora microrugosa (Ibr.) S.,W. et B., L. simplex Naum., Punctatisporites solidus (Naum.) Byvsch., Trachytriletes minor Naum., Cyclogranisporites rugosus (Naum.) Oshurk., C. rotundus (Naum.) Oshurk., C. subrotundatus (Naum.) Oshurk., Lophotriletes magnus Naum., Apiculatisporis famenensis (Naum.) Oshurk., Retusotriletes pychovii Naum., $R$. communis Naum., R. simplex Naum., Verruciretusispora semilucensis (Naum.) Oshurk., Geminospora rugosa (Naum.) Obukh., G. micromanifesta (Naum.) Owens, G. micromanifesta (Naum.) Owens. var. collatatus Tschibr., G. nalivkinii (Naum.) Obukh., G. opipara (Naum.) Owens, G. semilucensa (Naum.) Obukh. \& M.Rask., G. cf. semilucensa (Naum.) Obukh. \& M.Rask., G. meonacanta (Naum.) Tschibr., G. compacta (Naum.) Obukh., G. compta (Naum.) Arch. var. densispinosus Tschibr., G. parvibasilaris (Naum.) Byvsch., Kedoesporis livnensis (Naum.) Obukh., K. angulosus (Naum.) Obukh., Diaphanospora rugosa (Naum.) Byvsch., Ambitisporites conspersus (Naum.) Oshurk., A. definitus (Naum.) Oshurk., A. simplex (Naum.) Oshurk., A. extensus (Naum.) Oshurk. var. major Naum., A. extensus (Naum.) Oshurk. var. minor Naum., Stenozonotriletes pumillus (Waltz.) Isch., S. rugosus Nekr., S. recognitus Naum. var. minor Naum., S. conformis Naum., S. laevigatus Naum., Lophozonotriletes curvatus Naum., Brochotriletes foveolatus Naum. var. major Naum. Доминирующими родами в комплексе являются: Geminospora (16,1\%), Stenozonotriletes u Ambitisporites (15,6\%), Retusotriletes $(16,9 \%)$. В составе рода Geminospora наиболее характерны виды: Geminospora rugosa (Naum.) Obukh., G. semilucensa (Naum.) Obukh. \& M.Rask., G. opipara (Naum.) Owens, G. micromanifesta (Naum.) Owens var. collatatus Tschibr. и др. Довольно разнообразны виды в составе рода Retusotriletes: $R$. communis Naum. (8,6\%), R. simplex Naum., R. pychovii Naum. Наибольшее видовое разнообразие наблюдается в составе двух родов, ранее составлявших один: Stenozonotriletes и Ambitisporites. Значительное процентное содержание у видов рода Kedoesporis: K. livnensis (Naum.) Obukh., Kedoesporis angulosus (Naum.) Obukh. В комплексе также присутсвуют миоспоры с простым строением экзины родов Leiotriletes (6,6\%), Cyclogranisporites (10,7\%), Trachytriletes (1,0\%), Punctatisporites (1,0\%).

Позднее, миоспоры изучались из даугавских отложений скв. 9 и скв.5 на территории Латвии и 


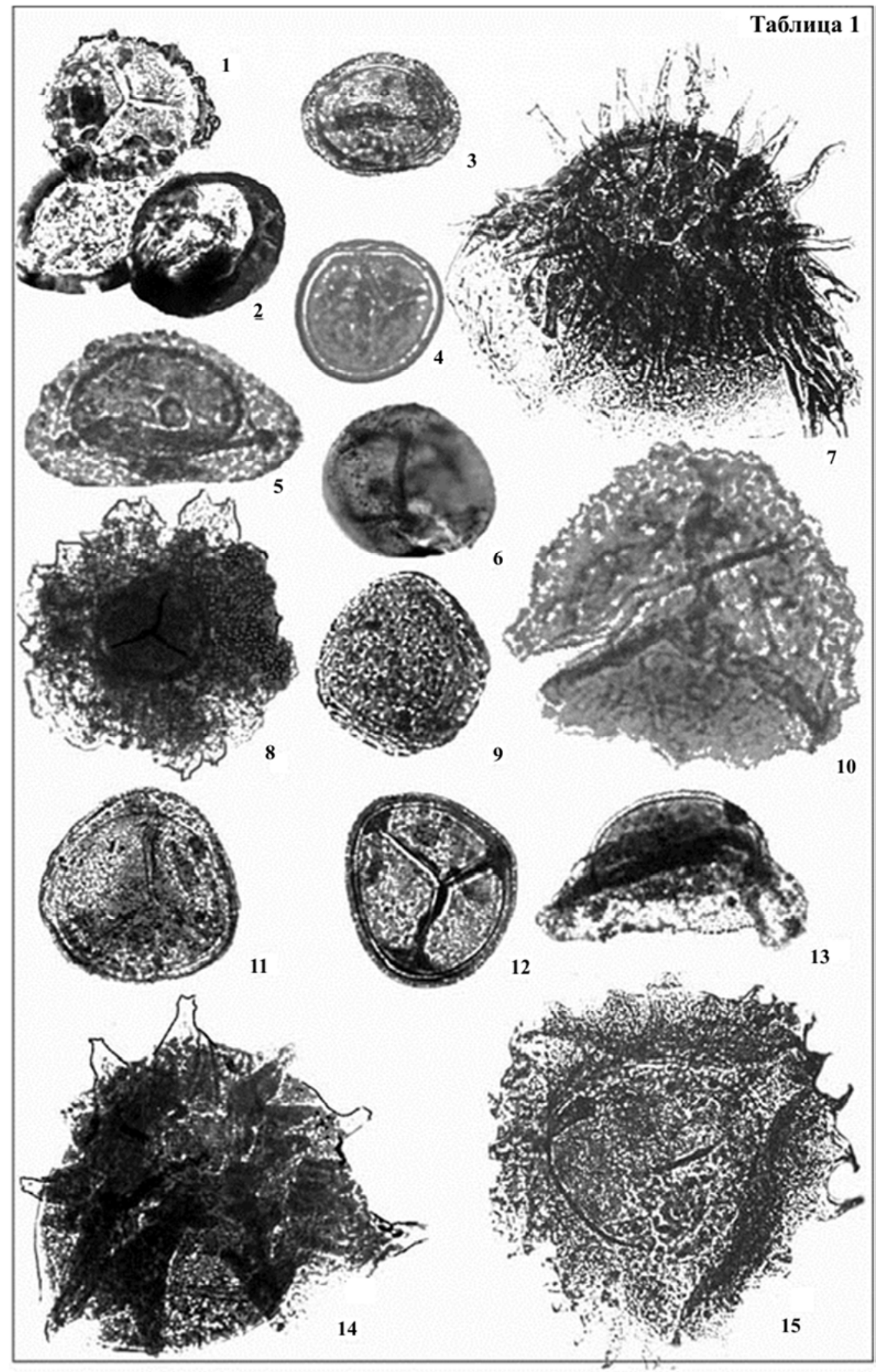

Таблица 1. Фиг. 1-15. Комплекс миоспор из отложений даугавского горизонта: 1- Lophozonotriletes scurrus Naum.; 2 - Archaeozonotriletes variabilis Naum.; 3 - Archaeoperisaccus ovalis Naum.; 4 - Stenozonotriletes formosus Naum.; 5 - Archaeoperisaccus concinnus Naum.; 6 - Apiculiretusispora verrucosa (Caro-Moniez) Streel; 7 Archaeotriletes comspicuus Naum.; 8 - Ancyrospora laciniosa (Naum.) Mants.; 9 - Convolutispora subtilis Owens; 10 - Calyptosporites krestovnikovii (Naum.) Oshurk.; 11 - Geminospora micromanifesta (Naum.) Owens; 12 - G. nalivkinii (Naum.) Obukh.; 13 - Archaeoperisaccus mirus Naum.; 14 - Ancyrospora fidus (Naum.) Obukh.; 15 Hymenozonotriletes argutus Naum.; ВГУ, № L2011д/29-31. 
коррелировались с комплексом миоспор из семилукских отложений ЦДП $[11,12,13]$.

\section{Современный анализ}

комплексов миоспор даугавского горизонта

В данной работе изучение комплекса миоспор из даугавского горизонта проводилось по двум скважинам, расположенным на территории Латвии: № 5 и № 1-Т и в Псковской области - скв. № 9. Отличительной особенностью обоих комплексов является первое появление в нижней части горизонта рода Archaeoperisaccus (A. ovalis Naum.) (табл. 1, Фиг. $3)$, видовое разнообразие которого увеличивается в верхней части горизонта (A. concinnus Naum., A. mirus Naum.) (табл. 1, Фиг. 5, 13), а также доминирование родов: Geminospora, Stenozonotriletes u Ambitisporites. Но есть некоторые различия между доминирующими родами миоспор в комплексах из разрезов трех скважин. В комплексах из скв. № 5 и скв. № 1-Т доминируют виды родов: Geminospora, Stenozonotriletes, Ambitisporites, Lophozonotriletes: Geminospora rugosa (Naum.) Obukh., G. semilucensa (Naum.) Obukh. \& M. Rask., Stenozonotriletes laevigatus Naum., Ambitisporites definitus (Naum.) Oshurk., Lophozonotriletes curvatus Naum. Разнообразие в составе рода Geminospora (13\%), Stenozonotriletes (5\%) и Ambitisporites (5\%) значительно меньше, чем в комплексе из скв.№ 9 (45,5\%). Миоспоры рода Lophozonotriletes составляют $13 \%$, но представлены преимущественно одним видом - Lophozonotriletes curvatus Naum., реже появляется второй вид этого рода - L. scurrus Naum. В комплексе из скв. № 1-Т необходимо отметить вспышку разнообразия крупных миоспор с бифуркатными выростами: Archaeotriletes conspicuus Naum., Ancyrospora fidus (Naum.) Obukh. (табл. 1, Фиг. 7, 14). В составе комплекса из скв. № 9 доминируют следующие миоспоры: Geminospora rugosa (Naum.) Obukh., G.compacta (Naum.) Obukh., G. plicata Owens, G. opipara Owens, G. semilucensa (Naum.) Obukh.\& M.Rask., G. micromanifesta (Naum.) Owens, G. nalivkinii (Naum.) Obukh. (табл. 1, Фиг. 11, 12), Apiculiretusispora verrucosa (Caro-Moniez) Streel (табл. 1, Фиг. 6), Archaeozonotriletes variabilis Naum. (табл. 1, Фиг. 2), Hymenozonotriletes argutus Naum. (табл. 1, Фиг. 15), Calyptosporites krestovnikovii (Naum.) Oshurk. (табл. 1, Фиг. 10), Ancyrospora laciniosa (Naum.) Mants. (табл. 1, Фиг. 8); Convolutispora subtilis Owens (табл. 1, Фиг. 9), Kedoesporis livnensis (Naum.) Obukh., K. angulosus (Naum.) Obukh., Ambitisporites simplex (Naum.) Oshurk., A. definitus (Naum.) Oshurk., $A$. conspersus (Naum.) Oshurk., A. extensus (Naum.) Oshurk. var. major Naum., Stenozonotriletes conformis Naum., S. pumilus (Waltz) Isch., S. simplicissimus Naum., S. calamites Naum., S. formosus Naum. В составе рода Kedoesporis господствует вид Kedoesporis livnensis (Naum.) Obuch. - 3,1\%, а в отдельных образцах достигает 6\%. Присутствуют также миоспоры мелких и средних размеров с простой скульптурой: Calamospora microrugosa(Ibr.) S.W. et B., Punctati- sporites solidus (Naum.) Byvsch. Миоспоры с выраженными ареями: Retusotriletes communis Naum., R. simplex Naum., R. pychovii Naum., Verruciretusispora semilucensa (Naum.) Oshurk., в отложениях Псковской области получили более широкое развитие, чем в отложениях даугавского горизонта Латвии так же как и миоспоры рода Lophozonotriletes (3,6\%).

В. Р. Озолиня выделила единый III комплекс миоспор для даугавских отложений Латвии, который характеризовался преобладанием родов: Stenozonotriletes, Verrucosisporites, Lophozonotriletes и отличается от систематического состава комплекса установленного нами. При сопоставлении даугавского комплекса Латвии с семилукским комплексом ЦДП [11-14] удалось установить, что основная часть видов является общими. Доминирующими для комплексов обоих горизонтов являются миоспоры родов Geminospora, Stenozonotriletes и Ambitisporites. В семилукском комплексе несколько меньше миоспор рода Stenozonotriletes, господствует Perotrilites donensis (Rask.) M. Rask. (10,4\%), отсутствующий в даугавских, а в даугавских - Kedoesporis livnensis (Naum.) Obuch. (3,1\%). Миоспоры с развитыми ареями широко развиты как в семилукском так и в даугавском горизонтах. Они представлены в основном видами: $R$. communis Naum., $R$. pychovii Naum., Verruciretusispora semilucensa (Naum.) Oshurk. Миоспоры с крупнобугорчатой скульптурой экзины в семилукских отложениях имеют большее видовое разнообразие, чем в даугавских, но доминирующим видом для тех и других является Lophozonotriletes curvatus Naum. (1,9\%).

Т.о. комплекс миоспор, установленный в разрезе даугавских отложений в трех скважинах на территории Латвии и Псковской области России демонстрирует изменение видового состава по вертикали и соответствует двум миоспоровым зонам, установленным для Восточно-Европейской платформы [15]: Geminospora semilucensa - Perotriletes donensis (SD) и нижней части зоны Archaeoperisaccus ovalis - Verrucosisporites grumosus (OG).

\section{ЛИТЕРАТУРА}

1. Grewingk, C. Geologie von Liv- und Kurland. / C. Grewingk. - Dorpat, $1859 .-55 \mathrm{p}$.

2. Grewingk, C. Geologie von Liv- und Kurland mit Inbegriff einiger angrenzenden Gebiete / C. Grewingk // Arch. Naturk. Liv-, Est-, Kurlands. I. Ser. 1861. - Bd. 11. - P. 479-776.

3. Kraus, E. Studien zur ostbaltischen Geologie. I. Marine Transgressions-Stösse im baltischen Devon/ E. Kraus // L. U. Geol. Inst. Raksti, Riga. - 1927. - № 9. - P. 36-47.

4. Сорокин, B. C. Об этапности осадконакопления в ранне- и среднефранское время на Главном девонском поле / В. С. Сорокин // Бюл. МОИП, Отд. Геол., 1965. - №4. - С. 121-122. 5. Сорокин, В. С. Об этапности франского осадконакопления на Главном девонском поле / В. С. Сорокин // Материалы IV конференции геологов Прибалтики и Белоруссии. Минск. - 1966. - С. 98-101.

6. Сорокин, В. С. Ильменские слои и и стратиграфические аналоги в западной части Главного девонского поля / В. С. 
Сорокин // Вопросы геологии среднего и верхнего палеозоя Прибалтики. - Рига, Зинатне. - 1967. - С.85-105.

7. Liepiņš, $P$. Daži devona stratigrãfijas jautãjumi galvenã devona lauka rietumu dalã. / P. Liepiņš. - Latv.PSR ZA Vēstis. № 6. -1951 .

8. Озолиня, В. Р. Спорово-пыльцевой спектр франского яруса верхнего девона Латвийской ССР / В. Р. Озолиня / Франские отложения Латвийской ССР. Тр.10 ИГ АН ССР. Зинатне. Рига. - 1963. - С. 299-310.

9. Сорокин, В. С. Девон и карбон Прибалтики / В. С. Сорокин. - Рига, Зинатие, 1981. - 502 с.

10. Раскатова, М. Г. К палинологической характеристике ильменских отложений верхнего девона Псковской области / М. Г. Раскатова / Литология и стратиграфия осадочного чехла Воронежской антеклизы. Воронеж: Изд-во Воронеж. ун-та. - 1977. - Вып.4. - С. 90-93.

11. Корреляция семилукских отложений Русской плиты и Тимано-Печорской провинции методами палинологии /

ФГБОУ ВО «Воронежский государственный университет»

Раскатова Марина Георгиевна, доцент кафедры исторической геологии и палеонтологии, кандидат геолого-минералогических наук E-mail:mgraskatova@yandex.ru Тел.: +7 (473) 2208634
Л. Г. Раскатова [и др.] // Палинология в СССР. Новосибирск: Наука. 1988. - С. 84-87.

12. Раскатова, М. Г. Характеристика миоспоровых зон франских отложений Главного девонского поля // Актуальные проблемы палинологии на рубеже третьего тысячелетия: Тезисы докладов IX Всероссийской палинологической конференции. М.: ИГиРГИ. 1999. - С. 244-245.

13. Raskatova, M. G. Frasnian Miospore Assemblages and Zones of Southern Latvia and North-Western Russia (Pskov Region) / M. G. Raskatova, A. L. Jurina // Scientific Papers University of Latvia, Earth and Environmental Sciences. - 2012. - V.783. - P. 24-36.

14. Раскатова, Л. Г. Спорово-пыльцевые комплексы среднего и верхнего девона юго-восточной части Центрального девонского поля / Л. Г. Раскатова. - Воронеж. 1969. - 167 с. 15. Avkhimovich, V. I. Middle and Upper Devonian miospore zonation of Eastern Europe / V. I. Avkhimovich [et al.] // Bull. CentresRech. Explor. Prod. Elf Aquitaine. - 1993. - 17(1). - P. 79-147.

\section{Voronezh State University}

Raskatova M. G., associate professor, chair of Historical Geology and Palaeontology, Candidate of the Geological and Mineralogical Sciences

E-mail:mgraskatova@yandex.ru Tel.: +7 (473) 2208634 